\title{
COMPOSICIÓN FITOQUÍMICA DE LA Satureja brevicalyx Epling
}

\section{Autores:}

Andamayo Flores, D.: Valderrama Sueldo, M.; Castillo Andamayo, D.; Junchaya Yllescas, V.; Camposano Córdova, Y.; Espinoza Castillo, D.; Canales Tupac, M.

\section{RESUMEN}

Satureja brevicalyx Epling crece en la parte sur andina del Perú (Ayacucho, Apurimac, Cuzco y Puno), entre las altitudes de 3300-3800 msnm, dentro de la composición química del aceite esencial de Satureja brevicalyx podemos encontrar varios constituyentes como mentonas, pulegonas, linalol. Tradicionalmente se ha usado como digestivo, contra la gastritis, flatulencia y antiespasmódica.

\section{OBJETIVO:}

Identificar la composición química del extracto etanólico,Hexano/etanol y acuoso de la Satureja brevicalyx Epling para conocer los metabolitos secundarios que sean de interés biológico en la terapeútica.

\section{MÉTODOS:}

Las hojas fueron exudadas y deshidratadas a temperatura ambiente, obteniéndose un polvo seco de color verdoso al cual se sometieron a extracciones sucesivas con solventes de polaridad creciente. A los extractos obtenidos se realizaron ensayos fitoquímicos de identificación.

\section{RESULTADOS:}

El tamizaje fitoquímico,efectuado a los extractos etanólico, hexano/etanol y acuoso de la hojas ,demostró la existencia de varias familias de meta bolitos secundarios de interés biológico y farmacológico, entre los que se destacan, por su significativa presencia las, quinonas, flavonoides, alcaloides, fenoles, taninos

\section{CONCLUSIONES :}

De acuerdo a la presencia de los metabolitos secundarios presentes en las hojas de la Satureja brevicalyx Epling, así como los efectos farmacológicos reportados para el aceite esencial de la especie, sería importante efectuar nuevos estudios que sirvan como evidencias para avalar su empleo tradicional teniendo en cuenta la eficacia y seguridad de esta planta.

Palabras Clave: Satureja brevicalyx Epling, meta bolitos secundarios composición química .

\section{ABSTRACT}

Introduction: Epling brevicalyx savory grows in the southern Andes of Peru (Ayacucho, Apurimac, Cuzco and Puno), between altitudes of 3300-3800 $\mathrm{m}$, within the chemical composition of the essential oil of Satureja brevicalyx can find several constituents as mentonas, pulegonas, linalool. Traditionally it has been used as a digestive, against gastritis, flatulence and antispasmodic. 
Objective: To identify the chemical composition of the ethanol extract, hexane / ethanol and the aqueous brevicalyx Satureja Epling for secondary metabolites that are of interest in biological therapeutics.

Methods: The leaves were exuded and dehydrated at room temperature, obtaining a greenish dry powder which underwent successive extractions with solvents of increasing polarity. To the obtained extracts phytochemicals identification assays.

Results: The phytochemical screening, conducted at the ethanolic extracts, hexane / aqueous ethanol and the leaves, showed the existence of several families of secondary metabolites of biological and pharmacological interest, among which stand out for their significant presence of quinones, flavonoids, alkaloids, phenols, tannins.

Conclusions: According to the presence of secondary metabolites in the leaves of Satureja brevicalyx Epling and pharmacological effects reported for the essential oil of the species, it would be important to conduct further studies to serve as evidence to support its traditional use taking into account the efficacy and safety of this plant.

Keywords: savory brevicalyx Epling, chemistry secondary metabolites.

\section{INTRODUCCIÓN}

Las plantas nativas poseen numerosos meta bolitos secundarios de estructura variada cuya bioactividad no es del todo conocida. Muchas de éstas tienen excelentes actividades farmacológicas y microbiológicas. Se estima que aproximadamente el $80 \%$ de la población mundial utiliza las plantas medicinales como la única fuente de tratamiento frente a diversas enfermedades. A pesar del gran avance de la Industria Farmacéutica en los últimos años, las drogas modernas no están disponibles o éstas son demasiado caras para la gran mayoría de las personas de bajos recursos económicos. La mayoría de fármacos activos contra agentes infecciosos son derivados naturales o se elaboran a partir de estructuras sugeridas por productos naturales.

El género Satureja cuenta con más de 200 especies en el mundo, todas estas especies son de regiones templadas y tropicales de ambos hemisferios de la tierra. En el Perú se han identificado unas 26 especies en donde la Satureja brevicalyx es que se encuentra ubicada en las regiones alto andinas sureñas del Perú ${ }^{1}$.

La Satureja brevicalyx crece en la parte sur andina del Perú (Ayacucho, Apurimac, Cuzco y Puno), entre las altitudes de 3300-3800 msnm, es de predilección por laderas de suelos arenoarcillosos y pedregosos ${ }^{2,3}$. En cuanto a su descripción botánica es una planta de porte arbustiva perennifolio, erguido de $1.0-1.5 \mathrm{~m}$ de altura, aromática y pubescente. Hojas muy pequeñas, espatuladas, sésiles, verticiladas $y$ opuestas, de margen entero. Flores blancas, solitarias, axilares, tetrámeras, bilabiadas, cáliz gamosépalo, corola gamopétala, androceo con estambres didínamos, gineceo con ovario súpero, estilo apical y estigma simple. Florece en primavera y verano; según sus informaciones etnobotánicas y etnofarmacológicas es usada para resolver problemas gastrointestinales y para la corrección de desordenes menstruales. Es digestivo, contra la gastritis, flatulencia y antiespasmódica; también es usado como analgésico soasando las hojas en caso de dolores musculares y tortícolis ${ }^{1}$.

Dentro de la composición química del aceite esencial de Satureja brevicalyx podemos encontrar varios constituyentes como mentonas, pulegonas, linalol, etc.

Existen diversos estudios donde aceites esenciales de diversas plantas presentan efecto antibacteriano y dentro de su composición química se asemejan a la Satureja brevicalyx 
Epling..Por todo lo expuesto genera la importancia de identificar que composición quím i c a ti e ne el extracto etanólico,hexano/etanólico y acuoso de la Satureja brevicalyx Epling "INCA MUÑA ".para conocer los metabolitos secundarios que sean de interés biológico en la terapeútica.

La presente investigación utilizó el método experimental .

\section{OBJETIVO GENERAL}

Identificar la composición química del extracto etanólico, hexano/etanol y acuoso de la Satureja brevicalyx Epling para conocer los metabolitos secundarios que sean de interés biológico en la terapeútica.

\section{OBJETIVOS ESPECÍFICOS}

Realizar la casificación taxonómica de la Satureja brevicalyx Epling .

Identificar los metabolitos secundarios de la Satureja brevicalyx Epling siguiendo la ruta de la marcha fitoquímica

\section{CLASIFICACIÓN TAXONÓMICA}

La clasificación taxonómica de la Satureja brevicalyx, según el sistema de clasificación de A. Cronquist, la especie se ubica en la siguiente categoría taxonómica:

\begin{tabular}{ll} 
DIVISIÓN & : Magnoliophyta \\
CLASE & \multicolumn{1}{c}{ : Magnoliopsida } \\
SubCLASE & :Asteridae \\
ORDEN & : Lamiales \\
FAMILIA & : Lamiaceae \\
GÉNERO & : Satureja \\
ESPECIE & :Satureja brevicalyx Epling
\end{tabular}

Sinonimia vulgar: urq muña, wayra muña, sacha muña, muña, inca muña, salqa muña, cjunumuña, cjuna, konocy orégano de los incas ${ }^{1}$.

\section{MATERIALES YMÉTODOS}

Materiales

\section{Material de Laboratorio (Vidrio)}

Tubos de ensayo $13 \times 100$ tapa rosca, láminas cubre objetos, láminas porta objetos, matraces Pyrex $/ 300 \mathrm{~mL}$, placas petri Pyrex $/ 10 \mathrm{~cm}$ diâmetro, frascos estériles para dosis, placa socavada,pera de decantación /250Ml,vasos/250mL,agitador de vidrio, pipetas de $2 / \mathrm{ml}, 5 / \mathrm{mL}$

\section{Equipos}

Balanza analítica Ohaus, equipo de destilación ,equipo de reflujo, cocina, baño maría ,placa socavada,bomba al vacio

\section{Reactivos}

Alcohol etílico, Metanol, Dimetil Sulfocido, Alcohol amílico, Limadura de magnesio, Hidróxido de sodio, Acido pícrico, Acido bórico P.A., Acido perclórico P.A., Acido sulfúrico Q.P., Dicloruro de mercurio, Ferrocianuro de potasio, Fosfato monopotasico, lodo resublimado, Yoduro de Bismuto, Tricloruro Férrico, Alcohol etílico, Hexano, Nitrato de bismuto, Nitroprusiato de sodio, Piridina, Sulfato de sodio anhidro, Tricloruro de antimonio, Tungstato sódico, Ácido clorhídrico, Ácido ortofosforico, Dimetilsulfóxido, Diclorometano, Ácido silicotungstico, Carbonato de sodio, Fosfato ácido disodic36o, Hidróxido de amonio, Hidroxilamina clorhidrato, Molibdato de amonio, Nitrato de plata, Reineckato de amonio, Tetracloruro de carbono, Vanadato de amonio, Acido acético, Acido cítrico, Ácido tricloroacético, Acetona, Amoniaco, Anhídrido acético, Benceno, Cloroformo, Formaldehído, Tolueno, Vainillina y Agua destilada.

\section{MUESTRA VEGETAL}

Las hojas de las plantas de Saturja brevicalyx Epling "INCA MUÑA "fueron recolectadas de aquellas plantas que crecen en la parte sur andina del Perú Ayacucho,entre las altitudes de 33003800 msnm,.

La muestra recolectada fue trasladada a los 
laboratorios de Química Orgánica de la carrera de Farmacia y Bioquímica de la Universidad Privada de Huancayo "Franklin Roosevelt", donde fueron exudadas y deshidratadas a temperatura ambiente, obteniéndose un polvo seco de color verdoso, almacenándose en frascos de vidrio color ámbar para los análisis de los principales principios activos, para lo cual se sometieron a extracciones sucesivas con solventes de polaridad creciente. A los extractos obtenidos se realizaron ensayos fitoquímicos de identificación.

\section{IDENTIFICACIÓN DE LOS PRINCIPALES COMPONENTES QUÍMICOS}

Con cada una de las fracciones obtenidas, se realizaron diferentes ensayos con reacciones químicas de identificación mediante cambios de color o formación de precipitados, para determinar la presencia de metabolitos secundarios: flavonoides (Shinoda), compuestos fenólicos (cloruro férrico), alcaloides (Hager, Dragendorff, Mayer y Wagner), triterpenos y esteroides (Liebermann-Buchard), quinonas (Bortrager), compuestos lactónicos y cumarinas (Baljet), antocianidinas (Rosemhein), azúcares reductores (Fehling) y saponinas (Molisch) presentes en las fracciones A, B, C, D, E y F; según corresponda .

\section{PRIMERAFASE}

Se tomó una muestra de $50 \mathrm{mg}$ de la planta que fue depositado en frasco ámbar, que contenía 100 $\mathrm{mL}$ de etanol $96 \%$ agitando constantemente para posteriormente calentarlo ligeramente. Luego se dejó enfriar para separar $10 \mathrm{~mL}$ del sobrenadante que se le denominó la Fracción "A", la cual fue sometida a reacciones de identificación de fenoles, flavonoides y taninos, lo restante se llevó a baño maría para concentrar.

\section{SEGUNDAFASE}

Al concentrado obtenido se agregó $30 \mathrm{~mL}$ de $\mathrm{HCl}$ al $1 \%$, posteriormente se calentó a $50^{\circ} \mathrm{C}$ por 15 minutos, luego se dejó enfriar y se filtró, obteniéndose la fracción "B" (insoluble), posteriormente se agregó al concentrado $15 \mathrm{ml}$ de $\mathrm{HCl}$ al $1 \%$ realizando nuevamente el procedimiento anterior obteniéndose una nueva fase insoluble que se unió a la obtenida anteriormente sometiéndose a reacciones de identificación de esteroides y quinonas. Posteriormente se unió las dos soluciones solubles que constituyó la solución ácida.

\section{TERCERAFASE}

Posteriormente se concentró la solución ácida hasta $45 \mathrm{~mL}$ en baño maría alcalinizándola con hidróxido de amonio hasta un $\mathrm{pH}$ de 7-8, obteniéndose la solución alcalina. A esta solución se agregó $50 \mathrm{~mL}$ de hexano/etanol (3:2) por dos veces, donde se formaron dos fases, orgánica y acuosa.

\section{CUARTAFASE}

La fase orgánica se lavó con $40 \mathrm{~mL}$ de agua, formándose dos fases (acuosa y orgánica) que posteriormente fueron separadas; a la fase orgánica se agregó sulfato de sodio para deshidratar, obteniéndose la fracción " $C$ ", la cual fue sometida a reacciones de identificación de cardenólidos, esteroides y alcaloides; y la fase acuosa que resulta de esta separación se unió a la fase acuosa obtenida en la tercera fase, obteniéndose la fase acuosa total.

\section{QUINTAFASE}

A la fase acuosa total se agregó $25 \mathrm{ml}$ de hexano formándose 2 fases, la fase orgánica y la fase acuosa, a la fase orgánica se agregó sulfato de sodio anhidro para deshidratar, obteniéndose así la fracción "D" la cual fue sometida a reacciones de identificación de flavonoides, esteroides, catequinas, alcaloides, cardenólidos y leucoantocianidinas; la fase acuosa se unió a la fase acuosa total, obteniéndose así la fracción "E", la cual se sometió a reacciones de identificación de flavonoides y leucoantocianidinas.

\section{SEXTAFASE}

Aun gramo de muestra se agregó $50 \mathrm{~mL}$ de agua, llevándolo luego a baño maría durante 15 minutos. 
Finalmente se filtró en caliente obteniéndose la fracción "F", la cual fue sometida a reacciones de identificación de Saponinas.

\section{RESULTADOS}

Tabla 1. Metabolitos secundarios identificados en el extracto de la Satureja brevicalyx Epling .

\begin{tabular}{|c|c|c|c|}
\hline $\begin{array}{c}\text { FRACCIO } \\
\text { N }\end{array}$ & $\begin{array}{l}\text { METABOLITO } \\
\text { SECUNDARIO }\end{array}$ & REACCIÓN & RESULTADO \\
\hline \multirow{5}{*}{ A } & Fenoles & $\mathrm{FeCl}_{2}$ & + \\
\hline & \multirow[t]{2}{*}{ Flavonoides } & Shinoda & + \\
\hline & & Amonisco & + \\
\hline & \multirow[t]{2}{*}{ Taninos } & $\mathrm{FeCl}_{2}$ & + \\
\hline & & Gelatina & + \\
\hline \multirow[t]{2}{*}{ B } & Esteroides & Liebermann-Burchard & + \\
\hline & Quinonas & Borntranger & + \\
\hline \multirow{6}{*}{ C } & Cardenólidos & Baljet & + \\
\hline & Esteroides & Liebermann-Burchard & + \\
\hline & \multirow{4}{*}{ Alcaloides } & Draggendorff & + \\
\hline & & Hager & + \\
\hline & & Mayer & + \\
\hline & & Wagner & + \\
\hline \multirow{9}{*}{ D } & \multirow[t]{2}{*}{ Flavonoides } & Shinoda & - \\
\hline & & Amoniaco & - \\
\hline & Esteroides & Liebermsnn-Burchsard & - \\
\hline & \multirow{4}{*}{ Alcaloides } & Draggendorff & + \\
\hline & & Hager & + \\
\hline & & Mayer & + \\
\hline & & Wagner & - \\
\hline & Cardenólidos & Baljet & - \\
\hline & Leucosntocianidin & Rosenhein & - \\
\hline \multirow{3}{*}{ E } & Leucosntocianidin & Rosenhein & - \\
\hline & \multirow[t]{2}{*}{ Flavonoides } & Shinods & + \\
\hline & & Amonisco & + \\
\hline \multirow[t]{2}{*}{$\mathbf{F}$} & \multirow[t]{2}{*}{ Ssponinss } & Espums & + \\
\hline & & Molisch & + \\
\hline
\end{tabular}

LEYENDA: (-): Ausente. (+): Presente.

\section{CONCLUSIONES}

En el extracto alcohólico de la Satureja brevicalyx Epling que representa la fracción " $A$ " se encontraron los siguientes metabolitos: fenoles, flavonoides y taninos.

En el extracto ácido de la Satureja brevicalyx Epling se separó la fase insoluble y se le denomino la fracción "B" y se identificó la presencia de esteroides y quinonas .

La fracción ácida soluble se alcalinizó y posteriormente se extrajo con hexano/etanol y se separa la fase orgánica y se le denomino la fracción "C" donde se identificó la presencia de los meta bolitos : cardenólidos, esteroides y alcaloides,en la fase acuosa se adiciona hexano y se separa la fase orgánica que se le denominó fracción " $D$ " y se identificó alcaloides y cardenolidos y a la fase acuosa se le denominó fracción "E" y se identificó la presencia de flavonoides.

Al extracto acuoso se le denominó la Fracción "F" y se identificó la presencia de saponinas

\section{REFERENCIAS BIBLIOGRÁFICAS}

1. Carhuapoma Yance M. Composición química, actividad anti- Helicobacter pylori y antioxidante del aceite esencial de Satureja brevicalyx Epling "Urq muña" [tesis doctoral]. Lima: UNMSM; 2007.

2. Chumacero $A$, Iparraguirre $D$, Riofrío $O$, Salas E. Género Satureja (Lamiaceae) en la etnomedicina andina. [tesis pregrado]. Lima: UNMSM; 2003.

3. Carhuapoma YM. Plantas medicinales aromáticas nativas de la provincia de Huamanga y sus perspectivas económicas. [tesis pregrado]. Ayacucho: UNSCH; 2002.

4. Gros E, Pomilio A. Introducción al estudio de productos naturales. Argentina; 1985: 1-5.

5. Kuklinski C. Farmacognosia: Estudio de las drogas y sustancias medicamentosas de origen natural. Barcelona: Omega ediciones; 2003.p. 134-43

6. Chumacero A, Iparraguirre D, Riofrío $O$, Salas E. Género Satureja (Lamiaceae) en la etnomedicina andina. [tesis pregrado]. Lima: UNMSM; 2003.

7. Muñoz A, Castañeda $M$, Blanco $K$, Cárdenas C, Reyes J, Kouznetsov Stashenko E. Composición y capacidad antioxidante de especies aromáticas y medicinales con alto contenido de timol y carvacrol. Scientia et Technica 2007;33: 125-8.

Fecha de recepción: 02/04/2013 Fecha de aprobación: 08/04/2013 Correspondencia: Diana Andamayo Flores Email: dianaandamayo@hotmail.com 